\title{
Professional Confidence
}

\section{Goal 2: Life Skills}

Narrative: In a residential environment, it is imperative that students learn skills that will help them lead healthy, independent lives in their adolescence and beyond. Students will display growth as/evolve into competent, self-sufficient individuals that are capable of overcoming personal and professional challenges.

\section{Learning Outcomes:}

- Students will demonstrate competence in skills essential to thrive in a professional setting

- Students will demonstrate competence in personal life skills required to live independently

- Students will practice steps for positive decision making

- Students will develop an ethical mindset to approach difficult situations

\section{Goal 3: Interpersonal Intelligence}

Narrative: A thriving individual needs the skills to advocate for themselves and collaborate with others in a variety of situations. They should understand the impact of their actions on others. It involves effective verbal and nonverbal communication and the ability to entertain multiple perspectives

\section{Learning Outcomes:}

- Students will display effective interpersonal communication skills such as effective conflict resolution strategies, verbal and nonverbal reactions in social situations and how they differ amongst individuals. 
- Students will develop effective leadership skills

\section{Specific Lesson Outcomes:}

- Students will be able to increase their confidence in themselves (whether it may be in their schoolwork or career endeavors).

- Students will be able to combat different obstacles that stand in the way of their confidence (i.e. imposter syndrome).

\section{Implementation:}

I have provided a Google Slide that you are free to copy and adjust based off of your wing. (The script uses a lot of my own verbage, so feel free to change it depending on what fits you best.)

It's part lecture, part discussion.

Presentation Flow:

- Confidence Killers (and how to deal with them) and Discussion

- Confidence Boosters and Discussion

- Final Tips and Tricks from Students

*Optional: Padlet.com is a resource that you can use if you believe that you will have a better turnout of answers if students have the opportunity to post answers anonymously.

\section{Goal Assessment:}

On Canvas, an assessment should be made for the students with the following questions:

- Tell me one thing you are confident about when it comes to your professional self. (This can range from academics to your work life.)

- Tell me one thing you are insecure about when it comes to your professional self. Then, give me a tactic you can use to combat that feeling. 
- What's one new thing you learned from today's program?

\section{Sources}

\section{Youtube Videos:}

https://www.youtube.com/watch?v=MFd7I4iWeTg

\section{Articles:}

- https://www.businessnewsdaily.com/7828-women-career-confidence.html

- https://www.forbes.com/sites/jacquelynsmith/2012/03/06/how-to-be-more-con fident-at-work/?sh=57cec20fd9b2

- https://news.virginia.edu/content/study-overbearing-parents-lead-long-term-str uggles-relationships-education

- https://blossomtips.com/how-to-deal-with-controlling-parents/(note: this blog post could be better, but the tips are pretty solid)

\section{Images:}

Gonzalez, Rafael. Ash Playing Yu-Gi-Oh. Digital. 18 May, 2021. 